\title{
ESTIMATION OF LANDFILL GAS PRODUCTION
}

\section{LAK Perera}

Landfills accepting biodegradable organic waste produce significant amounts of methane rich landfill gas. Landfill gas, or $\mathrm{LFG}$, constitutes approximately equal quantities of methane and carbon dioxide. The global emissiors of methane from landfills are estimated to be about $10 \%$ of total anthropogenic emissions. Methane, a greenhouse gas, has a global warming potential (GWP) 21 times that of carbon dioxide over a 100-year time horizon. Therefore, control of methane from anthropogenic sources could substantially mitigate global warming. Considering these factors, there is renewed interest in controlling methane emissions from landfills.

Methane emissions from landfills can be controlled by extracting LFG for energy recovery, passive venting and flaring, or by riodifying the landfill cover to enhance passive oxidation of methane to carbon dioxide. To design any of the LFG control techniques prior knowledge of the amount of gas available is necessary

LFG production is site specific and depends on factors such as climatic conditions, waste characteristics, spatial heterogeneity, age of landfill, geometry of the landfill etc. The current techniques used to estimate LFG production are: theoretical calculations, generation models, experimental studies, LFG pumping tests and direct flux measurement. This paper discusses the advantages and disadvantages in using these methods to estimate LFG production. The paper concludes with a newly developed method at the University of Calgary, Canada to estimate LFG production. The method incorporates a geostatistical technique and a 1-D numerical model within a Geographic Information System (GIS). 